OPEN ACCESS

Edited by:

Petr Pavek,

Charles University, Czechia

Reviewed by:

Zhihao Liu,

United States Department of

Agriculture, United States

Sandra Kraljević Pavelić,

University of Rijeka, Croatia

*Correspondence:

Chen-Hsi Hsieh

chenicab@gmail.com;

chenci28@ym.edu.tw

${ }^{+}$These authors have contributed equally to this work

Specialty section:

This article was submitted to Drug Metabolism and Transport,

a section of the journal

Frontiers in Pharmacology

Received: 16 October 2019 Accepted: 03 February 2020

Published: 27 February 2020

Citation:

Liu J-H, Tsai T-H, Chen Y-J, Wang L-Y, Liu H-Y and Hsieh C-H (2020) Local Irradiation Modulates the Pharmacokinetics of Metabolites in 5-Fluorouracil-RadiotherapyPharmacokinetics Phenomenon.

Front. Pharmacol. 11:141. doi: 10.3389/fphar.2020.00141

\section{Local Irradiation Modulates the Pharmacokinetics of Metabolites in 5-Fluorouracil-Radiotherapy- Pharmacokinetics Phenomenon}

\author{
Ju-Han Liu ${ }^{1,2,3 \dagger}$, Tung-Hu Tsai ${ }^{2,3,4,5 t}$, Yu-Jen Chen ${ }^{2,6,7 t}$, Li-Ying Wang ${ }^{8,9}$, Hsin-Yu Liu ${ }^{10}$ \\ and Chen-Hsi Hsieh ${ }^{2,11,12 *}$
}

\begin{abstract}
${ }^{1}$ School of Nursing, National Taipei University of Nursing and Health Sciences, Taipei, Taiwan, 2 Institute of Traditional Medicine, National Yang-Ming University, Taipei, Taiwan, ${ }^{3}$ Graduate Institute of Acupuncture Science, China Medical University, Taichung, Taiwan, ${ }^{4}$ School of Pharmacy, College of Pharmacy, Kaohsiung Medical University, Kaohsiung, Taiwan, ${ }^{5}$ Department of Chemical Engineering, National United University, Miaoli, Taiwan, ${ }^{6}$ Departments of Radiation Oncology, Mackay Memorial Hospital, Taipei, Taiwan, ${ }^{7}$ Department of Medical Research, China Medical University Hospital, Taichung, Taiwan, ${ }^{8}$ School and Graduate Institute of Physical Therapy, College of Medicine, National Taiwan University, Taipei, Taiwan, 9 Physical Therapy Center, National Taiwan University Hospital, Taipei, Taiwan, ${ }^{10}$ Department of Family Medicine, Taipei Veterans General Hospital, Taipei, Taiwan, ${ }^{11}$ Division of Radiation Oncology, Department of Radiology, Far Eastern Memorial Hospital, New Taipei City, Taiwan, 12 Faculty of Medicine, School of Medicine, National Yang-Ming University, Taipei, Taiwan
\end{abstract}

Background: The effects of radiotherapy (RT) on the pharmacokinetics (PK) of 5-FU and 5-fluoro-5,6-dihydro-uracil (5-FDHU) were investigated by animal experiments.

Methods: Whole-pelvis RT with 0.5 and 2 Gy was delivered to Sprague-Dawley rats. 5FU at $100 \mathrm{mg} / \mathrm{kg}$ was intravenously infused $24 \mathrm{~h}$ after radiation. The pharmacokinetics of 5-FU and 5-FDHU in the plasma and bile system were calculated.

Results: The areas under the concentration versus time curve (AUC) of 5-FU in the plasma were reduced by local irradiation by $23.7 \%$ at 0.5 Gy $(P<0.001)$ and $35.3 \%$ at 2 Gy $(P<0.001)$. The AUCs of 5-FDHU were also reduced by $21.4 \%$ at 0.5 Gy $(P<0.001)$ and $51.5 \%$ at 2 Gy $(P<0.001)$. Irradiation significantly increased the clearance values (CLs) of 5 -FU by $30.6 \%$ at 0.5 Gy and $50.1 \%$ at 2 Gy, respectively. The CLs of 5-FDHU were increased by $27.2 \%$ at 0.5 Gy and $106 \%$ at 2 Gy. The AUCs of 5-FU in the bile were increased by $36.7 \%$ at 0.5 Gy $(P<0.001)$ and $68.6 \%$ at 2 Gy $(P=0.005)$. The AUCs of $5-$ FDHU in the bile were increased by $40.3 \%$ at $0.5 \mathrm{~Gy}(\mathrm{P}<0.001)$ and $248.1 \%$ at $2 \mathrm{~Gy}(\mathrm{P}<$ 0.001). The CLs of 5-FU in the bile were increased by $31.8 \%$ at 0.5 Gy and $11.2 \%$ at 2 Gy. However, the CLs of 5-FDHU in the bile were decreased by $29.1 \%$ at 0.5 Gy and $71.0 \%$ at 2 Gy.

Conclusion: Both conventional and low-dose irradiation can affect the pharmacokinetics of 5-FU and its metabolite, 5-FDHU. RT plus 5-FU could cause more adverse events than 5-FU alone by increasing the AUC ratio of 5-FU/5-FDHU. Irradiation decreases the AUC of 5-FU in the plasma, which may cause poor clinical outcomes.

Keywords: 5-fluorouracil, 5-fluoro-5,6-dihydrouracil, radiotherapy, pharmacokinetics, HPLC-UV, irradiation 


\section{INTRODUCTION}

Five-fluorouracil (5-FU) a traditional chemotherapeutic agent used in concurrent chemoradiation therapy (CCRT) to enhance the radiotherapy (RT) effects in rectal cancer patients (Fisher et al., 1988). Compared to surgery or RT alone, adjuvant CCRT (Wolmark et al., 2000) or neoadjuvant CCRT (Bosset et al., 2006) improves the locoregional control and overall survival in rectal cancer patients by $10 \%-15 \%$.

More than half of the catabolic activity of 5-FU in the liver through the dihydropyrimidine dehydrogenase (DPD) pathway generates toxic 5-fluoro-5,6-dihydro-uracil (5-FDHU), followed by fluoroureidopropionic acid and $\alpha$-fluoro- $\beta$-alanine (Wasternack, 1980; Heggie et al., 1987; Bocci et al., 2000). The cytosolic enzyme DPD in the catabolism of $5-\mathrm{FU}$ is widely expressed in the body (Lu et al., 1993; Van Kuilenburg et al., 1997; Mcleod et al., 1998). The increased AUC ratio of 5-FU/5FDHU is associated with adverse events (Di Paolo et al., 2001), and the modulation of the catabolic pathway of 5-FU has an impact on the side effects and adverse reactions (Ezzeldin and Diasio, 2004).

Pharmacokinetics is the study of the kinetics of a drug and/or its metabolites in the body and what the body does to the drugs (1991). In the past, RT has been used as a local treatment (Elsasser and Scholz, 2007). Growing evidence shows that the systemic pharmacokinetics (PK) of anticancer drugs can be modulated by local RT with different RT doses; this is called the RT-PK phenomenon (Hsieh et al., 2010; Hsieh et al., 2013; Hsieh et al., 2015; Chen et al., 2017). The area under the plasma concentration versus time curve (AUC) of 5-FU is reduced by RT (Hsieh et al., 2015), and the excretion of 5-FU is facilitated by RT (Hsieh et al., 2011).

However, whether RT modulates the PK of the metabolite of 5-FU, 5-FDHU, remains unclear. The current study investigates the interaction between RT and the pharmacokinetics of 5-FU and its metabolite in rats. The goal of the current study is to provide clinicians with more information about the interaction between RT, 5-FU, and 5-FDHU and to improve daily practice.

\section{MATERIALS AND METHODS}

\section{Reagents and Materials}

5-FU, 5-FDHU, amoxicillin (internal standard), and urethane were provided by Sigma-Aldrich Chemicals (St. Louis, MO, USA). Potassium dihydrogen phosphate $\left(\mathrm{KH}_{2} \mathrm{PO}_{4}\right)$, potassium hydroxide $(\mathrm{KOH})$, phosphoric acid $\left(\mathrm{H}_{3} \mathrm{PO}_{4}\right)$, and HPLC-grade methanol were purchased from E. Merck (Darmstadt, Germany). For all aqueous solutions in the experiment, deionized water from Millipore (Milford, MA, USA) was used.

5-FU and 5-FDHU were dissolved in methanol to produce a standard solution $(1 \mathrm{mg} / \mathrm{ml})$ and were diluted into Eppendorf tubes as a stock solution $(10 \mu \mathrm{g} / \mathrm{ml})$. The working solution was prepared by diluting the stock solution in $50 \%(\mathrm{v} / \mathrm{v})$ methanol to obtain the following concentrations: $0.1,0.5,1,5,10$, and $50 \mu \mathrm{g} /$ $\mathrm{ml}$. All stock solutions were stored in darkness at $-20^{\circ} \mathrm{C}$.

\section{Instrumentations and HPLC-UV Conditions}

The HPLC system consisted of chromatographic pumps (LC20AT; Shimadzu Co., Kyoto, Japan), an autosampler (SIL-20AC; Shimadzu Co., Kyoto, Japan), and a UV-Vis detector (SPDM20A; Shimadzu Co., Kyoto, Japan). All analytical samples were separated using a reverse-phase Diamonsil C18 column (250 mm $\times 4.6 \mathrm{~mm}$ i.d.; particle size $5 \mu \mathrm{m}$, Dikma, Lake Forest, China). The mobile phase for HPLC analysis consists of two solvent compositions: $10 \mathrm{mM}$ potassium dihydrogen phosphate $\left(\mathrm{KH}_{2} \mathrm{PO}_{4}\right)$ and methanol $(95: 5, \mathrm{v} / \mathrm{v})$. The $\mathrm{pH}$ of 10 $\mathrm{mM} \mathrm{KH} \mathrm{PO}_{4}$ was adjusted to $\mathrm{pH} 4.7$ using phosphoric acid or potassium hydroxide. The flow rate for the mobile phase was set at $1 \mathrm{ml} / \mathrm{min}$. The temperature in the autosampler was set at $4^{\circ} \mathrm{C}$, the analytical volume was $10 \mu \mathrm{l}$ for each sample, the UV-Vis detector scanned from 200 to $500 \mathrm{~nm}$, and the chromatographic profiles were monitored at $215 \mathrm{~nm}$ for $5-\mathrm{FU}$ and 5-FDHU.

\section{Preparation of 5-FU and 5-FDHU Plasma Extraction}

The sample extract preparation was conducted as follows. First, $50 \mu \mathrm{l}$ of rat plasma was mixed with $10 \mu \mathrm{l}$ of internal standard (amoxicillin) solution and $140 \mu \mathrm{l}$ of methanol for protein precipitation. The samples were vortex-mixed for $5 \mathrm{~min}$ and centrifuged at $13,000 \times \mathrm{g}$ at $4^{\circ} \mathrm{C}$ for $10 \mathrm{~min}$. The supernatants were purified through a $0.22-\mu \mathrm{m}$ supernatant filter prior to HPLC-UV analysis.

\section{METHOD VALIDATION}

\section{Calibration Curves}

The calibration curves ranged in concentration from 0.1 to 50 $\mu \mathrm{g} / \mathrm{ml}$ for the blood. The linearity of the assay was checked using the coefficient of determination $\left(r^{2}\right)$ for the calibration curve, which should be greater than 0.995 . The limit of detection (LOD) was determined at the concentration that generates a signal-tonoise ratio of 3 , and the lower limit of quantification (LLOQ) was defined as the lowest concentration of the linear regression that yields a signal-to-noise ratio of 10 .

\section{Extraction Recovery}

5 -FU and 5-FDHU were diluted to $0.5,5$, and $50 \mu \mathrm{g} / \mathrm{ml}$ in the mobile phase. Set 1: The stock solutions of 5-FU and 5-FDHU were mixed with $10 \mu \mathrm{l}$ of amoxicillin (I.S.) solution and diluted to $0.5,5$, and $50 \mu \mathrm{g} / \mathrm{ml}$ in the mobile phase. Set 2: A total of $10 \mu \mathrm{l}$ of standard solution was added to $50 \mu \mathrm{l}$ of blank plasma, $10 \mu \mathrm{l}$ of amoxicillin (I.S.) solution, and $130 \mu \mathrm{l}$ of methanol and prepared as described in the sample preparation section. A pre-extraction sample of 5-FU and 5-FDHU was prepared and used for HPLCUV analysis. The recovery was calculated as the peak area of Set 2 divided by the peak area of Set 1 .

\section{Accuracy and Precision Evaluation}

The accuracy and precision evaluation methods were based on the Food and Drug Administration (FDA) guidelines [34]. The accuracy was estimated as bias $(\%)=($ observed concentration - 
nominal concentration) $\times 100 /$ nominal concentration. The precision was calculated as the relative standard deviation, RSD \% $=(S D) \times 100 /$ observed concentration. The inter- and intra-day precision ( $\% \mathrm{RSD}$ ) and accuracy (\% bias) were less than $15 \%$ for all analytes at low, medium, and high QC concentrations according to the biological method validation guidelines of the FDA [34]. The precision and accuracy of this analytical method were verified by preparing six identical calibration curves on the same day (intraday) and on six successive days (interday). In addition, five conditions were evaluated for the stability study, including short-term storage at room temperature, long-term storage, three freeze-thaw cycles, post-preparative, and stock solution stability. Calibrations in six replications on the same day (intra-day) and on six successive days (inter-day) were achieved to verify the accuracy and precision. 5-FU and 5FDHU were prepared at concentrations of $0.1,0.5,1,5,10$, and $50 \mu \mathrm{g} / \mathrm{ml}$. The calibration curve was described using the peak area ratio of 5-FU and 5-FDHU hydrochloride versus the concentration.

\section{Stability Evaluation}

According to the FDA guidelines, the stabilities of 5-FU and 5FDHU were evaluated using the following methods. 1) Shortterm: The samples were stored at room temperature $\left(25 \pm 3^{\circ} \mathrm{C}\right)$ for $4 \mathrm{~h}$ before analysis. 2) Post-preparative: The samples were kept at $8^{\circ} \mathrm{C}$ for $8 \mathrm{~h}$ in an autosampler before analysis. 3) Freeze and thaw: The samples were stored at $-20^{\circ} \mathrm{C}$ for $24 \mathrm{~h}$ and then thawed at room temperature. The freeze and thaw cycles were repeated three times. 4) Long-term: The samples were kept at $-20^{\circ} \mathrm{C}$ for 30 days in darkness before analysis.

Concentrations of $0.5,5$ and $50 \mu \mathrm{g} / \mathrm{ml}$ of 5 -FU and 5-FDHU were selected to measure stability. The relative error between the freshly prepared samples and the stored samples was calculated to determine the stability. The limitation of sample stability was defined as within $\pm 15 \%$, and LLOQ values were less than $\pm 20 \%$.

\section{EXPERIMENTAL ANIMALS}

The protocol was reviewed and approved by the Institutional Animal Experimentation Committee of National Yang-Ming University, Taipei, Taiwan, and by the Institutional Animal Care and Use Committee (IACUC, approval number 106DN22). Male Sprague-Dawley rats (250-280 g) were provided by the Laboratory Animal Center at National YangMing University (Taipei, Taiwan). The animals had access to water ad libitum and food (laboratory rodent diet 5P14, PMI Feeds, Richmond, IN, USA) and lived in a pathogen-free environment with a 12-h light-dark cycle. All animal experiments followed the guidelines and procedures for the care of laboratory animals at National Yang-Ming University.

The rats were anesthetized with urethane $1 \mathrm{~g} / \mathrm{ml}$ and achloralose $0.1 \mathrm{~g} / \mathrm{ml}(1 \mathrm{ml} / \mathrm{kg}$ by intraperitoneal injection) and were immobilized on a board when undergoing computed tomography for the imaging of the whole pelvic field. Conventional radiotherapy was used to deliver the radiation dose via the anterior-posterior (AP) and PA portals (Figure 1A)
(Hsieh et al., 2011). The experimental animals were randomized to the control, 0.5 Gy followed by 5-FU and 2 Gy followed by 5-FU groups. Each group's data were collected from six rats. Dosages of 0.5 and 2 Gy for the rats and $100 \mathrm{mg} / \mathrm{kg}$ as a feasible 5 -FU dose in rats to examine the 5-FU pharmacokinetic parameters were determined from the results of previous reports (Hsieh et al., 2010; Hsieh et al., 2011; Hsieh et al., 2015). Twenty hours after RT,

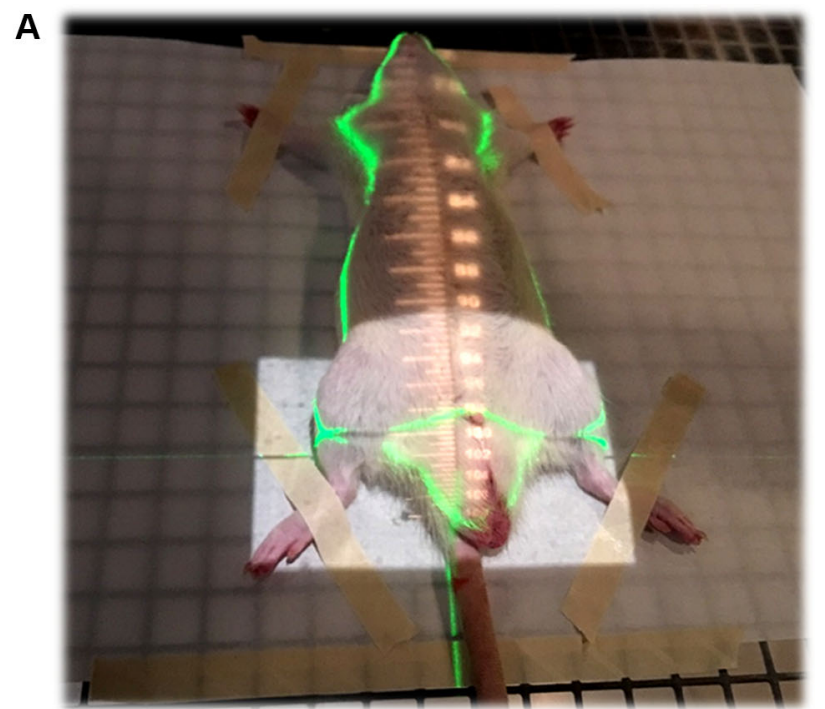

B

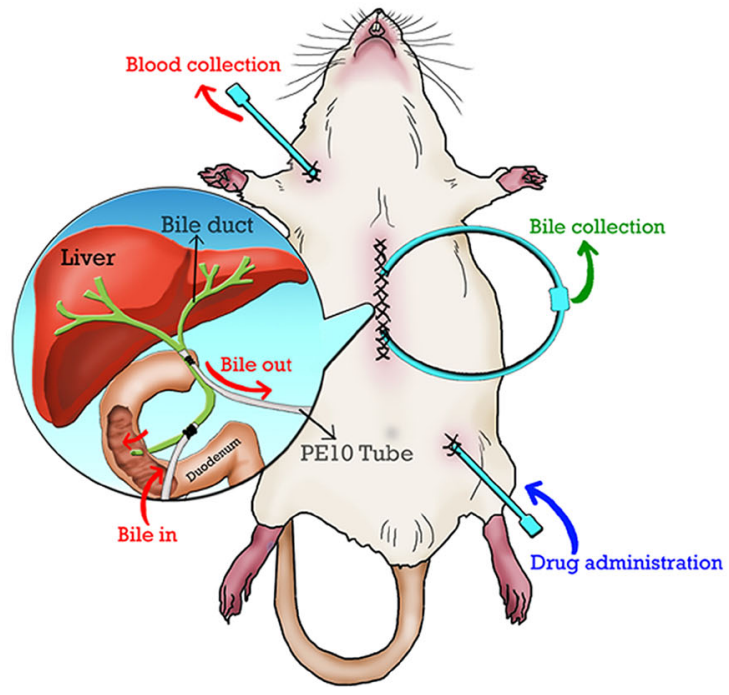

FIGURE 1 | (A) The irradiation field of the whole pelvis. The cranial margin was set at the top of the bilateral iliac crest for the whole pelvic field. Conventional radiotherapy was used to deliver the radiation dose via the anterior-posterior (AP) and PA portals. (B) Illustration of the bile duct cannulated rat model under anesthesia in this study. Exteriorization of the PE10 tube was prepared before bile duct catheterization. PE10 cannula was fixed to the bile duct (two positions near the liver and duodenum) by a surgical knot, and the wound was closed by sutures after duct cannulation was completed. The bile of the rat can flow into the circulation system when the pipes of the bile ducts are connected. 5-FU was administered via PE50 cannula into the femoral vein, and blood was collected through PE50 cannula from the jugular vein. 
the rats were administered $100 \mathrm{mg} / \mathrm{kg}$ of 5 -FU in $2 \mathrm{ml}$ of normal saline by intravenous infusion into the femoral vein over a 2-min period (Hsieh et al., 2010) (Figure 1B). A 150- $\mu$ l blood sample was withdrawn from the jugular vein with a fraction collector according to a programmed schedule at 5, 15, 30, 45, and 60 min and $1.5,2,2.5$, and $3 \mathrm{~h}$ following drug administration. The total blood volume of rodents is approximately $7 \%$ of their body weight, and approximately $20 \%$ of total blood volume can be withdrawn (Lee and Goosens, 2015). Thus, the volume of a blood sample that can be collected from a Sprague-Dawley rat is approximately $19.6 \mathrm{ml}$. In the current study, the volume of blood sample for each time collection was $150 \mu \mathrm{l}$, so the total blood volume collection was below $10 \%$ of the total circulating blood volume to avoid affecting the physiological index of the rats. The blood samples were immediately centrifuged at $3300 \times g$ for 10 min. The resulting plasma $(50 \mu \mathrm{l})$ was added to $1 \mathrm{ml}$ of ethyl acetate in a clean tube, vortexed for $5 \mathrm{~min}$, and centrifuged at $5900 \times g$ for $10 \mathrm{~min}$. After centrifugation, the upper organic layer containing the ethyl acetate was transferred to a new tube and evaporated to dryness under flowing nitrogen. The dried residue was reconstituted with $50 \mathrm{ml}$ of Milli-Q water (Millipore). A 20- $\mu \mathrm{l}$ aliquot of the solution was injected into the high-performance liquid chromatography-ultraviolet (HPLC-UV) detection system.

To collect the bile for a prolonged period, the bile was collected by a duct-cannulated rat model under anesthesia. Exteriorization of a PE10 tube was prepared before bile duct catheterization. A PE10 cannula was fixed to the bile duct (two positions at near liver and duodenum) by a surgical knot, and the wound was closed by sutures after duct cannulation was completed. The bile of the rat flowed into the circulation system when the pipes of the bile ducts were connected. 5-FU was administered via a PE50 cannula into the femoral vein, and blood was collected through a PE50 cannula from the jugular vein.

\section{Serum Cytokine Analysis}

The plasma levels of cytokines [transforming growth factor beta 1 (TGF- $\beta 1$ ), tumor necrosis factor alpha (TNF- $\alpha$ )] and matrix metalloproteinase-8 (MMP-8) obtained from the mouse blood samples were analyzed using enzyme-linked immunosorbent assay (ELISA) (R\&D Systems) according to the manufacturer's instructions.

\section{DATA ANALYSIS}

The pharmacokinetic parameters were determined by calculating each individual set of data with a non-compartmental model using WinNonlin Standard Edition Version 1.1 software (Scientific Consulting Inc., Apex, NC). The pharmacokinetic parameters calculated were the initial drug concentration of 5FU $\left(C_{0}\right)$, the maximum concentration and time of 5- FDHU $\left(C_{\max }, \mathrm{t}_{\max }\right)$, the area under the concentration versus time curve (AUC), the clearance (CL), the elimination half-life $\left(t_{1 / 2}\right)$, the volume of distribution at steady state (Vss) and the mean residence time (MRT). The statistical analyses were performed using analysis of variance in the SPSS 18.0 program (SPSS Inc., Chicago, USA) and SigmaPlot 10.0 software. All data are expressed as the mean \pm standard deviation (S.D.). One-way ANOVA was used for the comparison between groups, and statistically significant differences were defined as ${ }^{\star} P<0.05$ or ${ }^{* *} P<0.01$.

\section{RESULTS}

\section{Chromatographic Analysis and Method Validation}

The mobile phase of 5\% methanol and 95\% $10 \mathrm{mM} \mathrm{KH}_{2} \mathrm{PO}_{4}(\mathrm{v} /$ v) ( $\mathrm{pH} 4.7$ ) with a C18 column produced acceptable separation of 5 -FU and 5-FDHU in the experiment. The respective retention times of 5-FU and 5-FDHU were 6.8 and $5.8 \mathrm{~min}$, with good separation and no endogenous interference in the rat plasma samples, with good selectivity (Figures 2A-C). In the current study, the LODs of 5-FU and 5-FDHU in the plasma and in the bile were both $0.05 \mu \mathrm{g} / \mathrm{ml}$. Good linearity of the calibration curves $\left(r^{2}>0.999\right)$ over the range of $0.1-50 \mu \mathrm{g} / \mathrm{ml}$ was noted (Table 1). The absolute recoveries of 5-FU and 5-FDHU in plasma ranged from 102.9 to $103.2 \%$ and 99.3 to $105.4 \%$, respectively. Additionally, the absolute recoveries of 5-FU and 5-FDHU in bile ranged from $107.4 \%$ to $113.7 \%$ and $103.9 \%$ to $108.0 \%$, respectively (Table 2 ). The intra- and inter-day precision and accuracy values of 5-FU and 5-FDHU in the plasma and in the bile were within 15\% (Tables 3 and 4 ).

\section{RT-PK Pharmacokinetic Interaction Study}

The radiation at 2 Gy was the daily treatment dose for a human, and 0.5 Gy simulated the off-target dose in clinical practice. Compared with the sham RT group, as in previous reports (Hsieh et al., 2011; Hsieh et al., 2015), the current study also confirmed that local pelvic irradiation decreased the $\mathrm{AUC}_{\text {plasma }}$ of 5 -FU by $23.7 \%$ at $0.5 \mathrm{~Gy}(\mathrm{P}<0.001)$ and $35.3 \%$ at $2 \mathrm{~Gy}(\mathrm{P}<$ $0.001)$. Intriguingly, the $\mathrm{AUC}_{\text {plasma }}$ of $5-\mathrm{FDHU}$ was also reduced by $21.4 \%$ at $0.5 \mathrm{~Gy}(\mathrm{P}<0.001)$ and $51.5 \%$ at $2 \mathrm{~Gy}(\mathrm{P}<0.001)$. Additionally, pelvic irradiation significantly increased the clearance values (CLs) and the volume of distribution at steady state (Vss) of 5-FU by $30.6 \%$ and $16.7 \%$ at 0.5 Gy and $50.1 \%$ and $17.7 \%$ at $2 \mathrm{~Gy}$, respectively. Meanwhile, the CLs of 5-FDHU were increased by $27.2 \%$ at $0.5 \mathrm{~Gy}$ and $106 \%$ at $2 \mathrm{~Gy}$. The MRTs of 5FU and 5-FDHU in the plasma were decreased by $23.7 \%$ at 0.5 Gy and $18.2 \%$ at 2 Gy, respectively (Figures 3A, B; Table 5).

In contrast, the AUCs of 5-FU in the bile were increased by $36.7 \%$ at $0.5 \mathrm{~Gy}(\mathrm{P}<0.001)$ and $68.6 \%$ at $2 \mathrm{~Gy}(\mathrm{P}=0.005)$. Meanwhile, the AUCs of 5-FDHU in the bile were increased by $40.3 \%$ at $0.5 \mathrm{~Gy}(\mathrm{P}<0.001)$ and $248.1 \%$ at $2 \mathrm{~Gy}(\mathrm{P}<0.001)$. Additionally, pelvic irradiation significantly increased the respective MRTs of 5 -FU in the bile by $60.0 \%$ at 0.5 Gy and $125.0 \%$ at 2 Gy. Meanwhile, the clearance of 5-FU in the bile was increased by $31.8 \%$ at 0.5 Gy and $11.2 \%$ at 2 Gy. However, the 

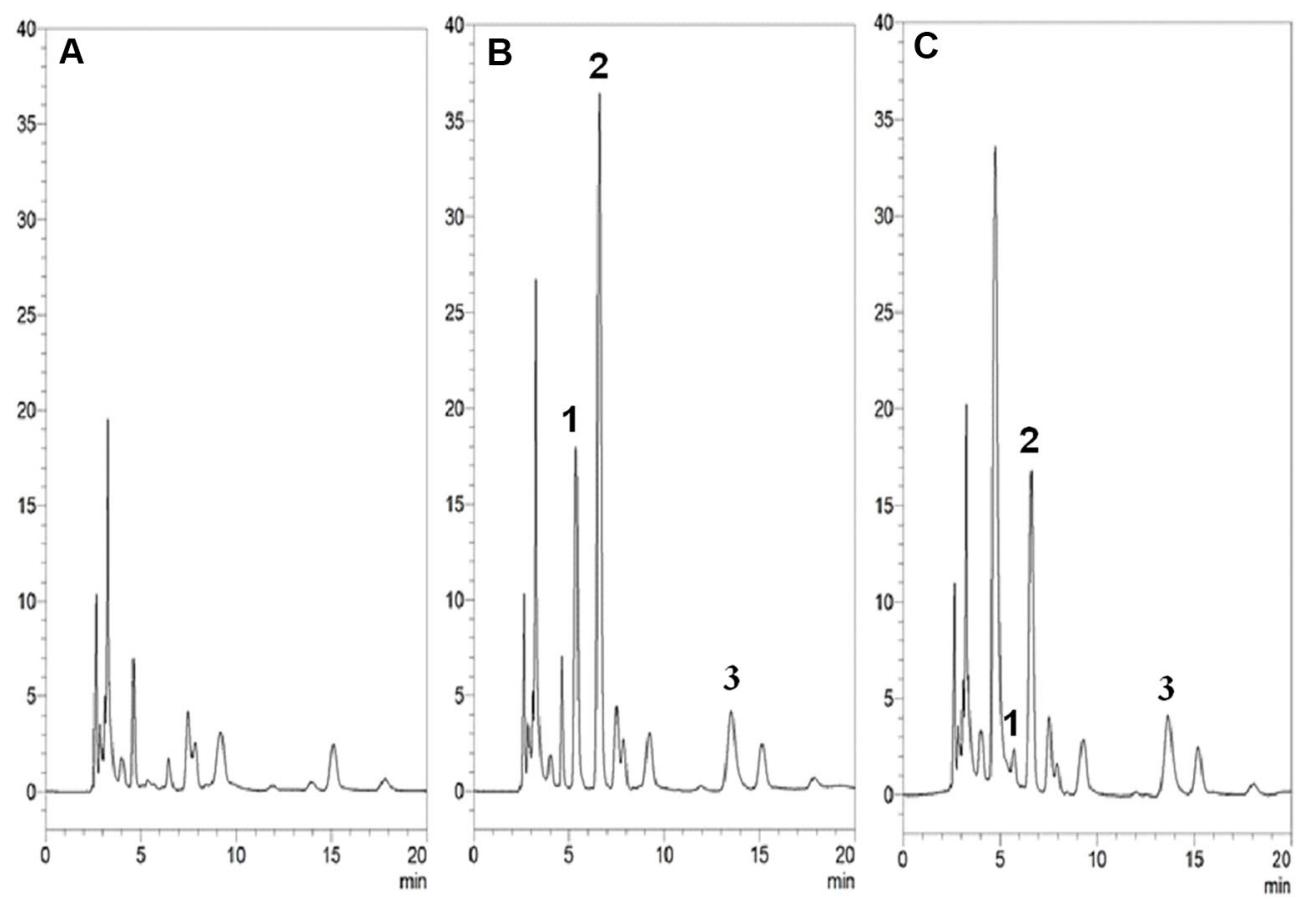

FIGURE 2 | HPLC-UV chromatograms of (A) blank plasma samples; (B) blank plasma samples spiked with 5-FU, 5-FDHU (10 $\mu \mathrm{g} / \mathrm{ml})$ and internal standard (10 $\mu \mathrm{g} /$ $\mathrm{ml})$; (C) blood sample containing 5-FU $(7.9 \mu \mathrm{g} / \mathrm{ml})$ and 5-FDHU $(1.1 \mu \mathrm{g} / \mathrm{ml})$ collected at $60 \mathrm{~min}$ after 5-FU (100 mg/kg, i.v.) administration alone. Peak 1: 5-FDHU and retention time of 5-FDHU was 5.3 min. Peak 2: 5-FU and retention time of 5-FU was $6.2 \mathrm{~min}$. Peak 3: amoxicillin and retention time of amoxicillin was 12.4 min.

TABLE 1 | Linear ranges, calibration curves, correlation coefficients $\left(r^{2}\right)$, and detection limits of 5-FU and $\mathrm{FUH}_{2}$ using HPLC-UV in the plasma and bile.

\begin{tabular}{lccccc}
\hline Compounds & $\begin{array}{c}\text { Linear range } \\
(\boldsymbol{\mu} \mathbf{g} / \mathbf{m l})\end{array}$ & Calibration curve & $r^{2}$ & $\begin{array}{c}\text { LLOQ } \\
(\boldsymbol{\mu} \mathbf{g} / \mathbf{m l})\end{array}$ & $\begin{array}{c}\text { LOD } \\
(\boldsymbol{\mu} \mathbf{g} / \mathbf{m l})\end{array}$ \\
\hline Plasma & & & & & \\
5-FU & $0.1-50$ & $\mathrm{y}=0.3263 x+0.0004$ & 1 & 0.1 & 0.05 \\
5-FDHU & $0.1-50$ & $\mathrm{y}=0.1907 x+0.0047$ & 1 & 0.1 & 0.05 \\
Bile & & & & & \\
5-FU & $0.1-50$ & $\mathrm{y}=0.3693 x-0.0011$ & 1 & 0.1 & 0.05 \\
5-FDHU & $0.1-50$ & $\mathrm{y}=0.2003 x-0.0009$ & 1 & 0.1 & 0.05 \\
\hline
\end{tabular}

$L L O Q$, lower limit of quantification was determined at a signal-to-noise ratio $(S / N)$ of 10; $L O D$, limit of detection was determined at a signal-to-noise ratio $(S / N)$ of 3 . clearances of 5-FDHU in the bile were decreased by $29.1 \%$ at 0.5 Gy and $71.0 \%$ at 2 Gy (Figures $\mathbf{4 A}$, B; Table 6).

\section{Cytokine Response During RT-PK of 5-FU}

Compared with the sham group, there were no significant differences in TGF- $\beta 1$ and TNF- $\alpha$ between the RT 0.5 Gy followed by 5 -FU and RT 2 Gy followed by 5-FU groups. MMP-8 expression increased by $27.7 \%$ in the RT 0.5 Gy followed by 5 -FU $(7319 \pm 3473)$ group. However, MMP-8 expression increased by $100 \%$ in the RT 2 Gy followed by 5 $\mathrm{FU}(11494 \pm 2606)$ group when compared with the sham group $(5733 \pm 2656, \mathrm{p}=0.005)$.

TABLE 2 | Extraction recoveries of 5-FU, 5-FDHU and amoxicillin (I.S.) from rat plasma and bile.

\begin{tabular}{|c|c|c|c|c|c|}
\hline \multirow[t]{2}{*}{ Con. ( $(\mu \mathrm{g} / \mathrm{ml})$} & \multirow[t]{2}{*}{$\begin{array}{l}\text { Spiked in the mobile phase } \\
\text { (Set 1) }\end{array}$} & \multicolumn{2}{|c|}{$\begin{array}{l}\text { Spiked before extraction } \\
\text { (Set 2) }\end{array}$} & \multicolumn{2}{|c|}{$\begin{array}{l}\text { Recovery } \\
\text { (\%) }\end{array}$} \\
\hline & & Plasma & Bile & Plasma & Bile \\
\hline 0.5 & $16137 \pm 74.61$ & $16611 \pm 353.8$ & $17330 \pm 1335$ & $102.9 \pm 0.020$ & $107.4 \pm 0.083$ \\
\hline 5 & $156962 \pm 7203$ & $161181 \pm 1401$ & $17748 \pm 20860$ & $102.8 \pm 0.042$ & $113.7 \pm 0.019$ \\
\hline 50 & $1598225 \pm 37459$ & $164982 \pm 28128$ & $1761897 \pm 109320$ & $103.2 \pm 0.023$ & $110.3 \pm 0.065$ \\
\hline 5 & $88523 \pm 5376$ & $97537 \pm 1124$ & $5299 \pm 3166$ & $110.4 \pm 0.057$ & $108.0 \pm 0.097$ \\
\hline 50 & $892893 \pm 58184$ & $963719 \pm 10026$ & $926613 \pm 43317$ & $108.2 \pm 0.062$ & $103.9 \pm 0.028$ \\
\hline \multicolumn{6}{|l|}{ I.S. } \\
\hline 10 & $98247 \pm 1942$ & $98929 \pm 815.3$ & $103691 \pm 3631$ & $100.7 \pm 0.028$ & $100.9 \pm 0.071$ \\
\hline
\end{tabular}

Data are expressed as the means \pm S.D. $(n=3)$. I.S.: amoxicillin; the recovery $(\%)=(\text { the peak area of Set 2/the peak area of Set } 1)^{\star} 100$. 
TABLE 3 | Inter-day and intra-day assay precision (\% RSD) and accuracy (\% Bias) values for the HPLC-UV method for the determination of 5-FU and 5-FDHU in rat plasma.

\begin{tabular}{|c|c|c|c|c|c|c|}
\hline \multirow{2}{*}{$\begin{array}{l}\text { Nominal } \\
\text { Con. ( } \mu \mathrm{g} / \mathrm{ml})\end{array}$} & \multicolumn{3}{|c|}{ Intra-day $(n=6)$} & \multicolumn{3}{|c|}{ Inter-day $(n=6)$} \\
\hline & $\begin{array}{c}\text { Observed } \\
\text { con. }(\mu \mathrm{g} / \mathrm{ml})\end{array}$ & $\begin{array}{c}\text { Accuracy } \\
\text { Bias (\%) }\end{array}$ & $\begin{array}{c}\text { Precision } \\
\text { RSD (\%) }\end{array}$ & $\begin{array}{c}\text { Observed } \\
\text { con. }(\mu \mathrm{g} / \mathrm{ml})\end{array}$ & $\begin{array}{c}\text { Accuracy } \\
\text { Bias (\%) }\end{array}$ & $\begin{array}{c}\text { Precision } \\
\text { RSD (\%) }\end{array}$ \\
\hline \multicolumn{7}{|l|}{$5-F U$} \\
\hline 0.1 & $0.095 \pm 0.01$ & -4.587 & 2.612 & $0.090 \pm 0.01$ & -10.14 & 12.12 \\
\hline 0.5 & $0.506 \pm 0.02$ & 1.284 & 3.700 & $0.475 \pm 0.04$ & -5.079 & 9.031 \\
\hline 1 & $0.959 \pm 0.06$ & -4.1485 & 6.638 & $0.921 \pm 0.09$ & -7.915 & 9.968 \\
\hline 5 & $4.999 \pm 0.18$ & -0.016 & 3.524 & $4.912 \pm 0.31$ & -1.754 & 6.319 \\
\hline 10 & $10.07 \pm 0.21$ & 0.731 & 2.036 & $10.45 \pm 0.60$ & 4.533 & 5.732 \\
\hline 50 & $50.04 \pm 0.05$ & 0.073 & 0.093 & $50.55 \pm 1.32$ & 1.106 & 2.604 \\
\hline \multicolumn{7}{|l|}{ 5-FDHU } \\
\hline 0.1 & $0.112 \pm 0.01$ & 11.61 & 11.04 & $0.105 \pm 0.01$ & 4.740 & 12.12 \\
\hline 0.5 & $0.528 \pm 0.03$ & 5.561 & 5.513 & $0.507 \pm 0.03$ & 1.430 & 5.027 \\
\hline 1 & $1.043 \pm 0.11$ & 4.253 & 10.16 & $1.055 \pm 0.10$ & 5.543 & 9.004 \\
\hline 5 & $5.082 \pm 0.15$ & 1.638 & 2.904 & $5.089 \pm 0.16$ & 1.784 & 3.116 \\
\hline 10 & $9.819 \pm 0.20$ & -1.814 & 2.021 & $9.975 \pm 0.31$ & -0.248 & 3.085 \\
\hline 50 & $50.05 \pm 0.16$ & 0.104 & 0.323 & $50.17 \pm 0.54$ & 0.343 & 1.086 \\
\hline
\end{tabular}

Data are expressed as the means \pm S.D. $(n=6)$ Precision $(\% R S D)=S . D . / C_{o b s}{ }^{*} 100$. Accuracy $(\%$ Bias $)=\left(C_{o b s}-C_{n o m}\right) / C_{n o m}{ }^{*} 100$.

TABLE 4 | Inter-day and intra-day assay precision (\% RSD) and accuracy (\% Bias) values for the HPLC-UV method for the determination of 5-FU and 5-FDHU in rat bile.

\begin{tabular}{|c|c|c|c|c|c|c|}
\hline \multirow{2}{*}{$\begin{array}{c}\text { Nominal } \\
\text { Con. }(\mu \mathrm{g} / \mathrm{ml})\end{array}$} & \multicolumn{3}{|c|}{ Intra-day $(n=6)$} & \multicolumn{3}{|c|}{ Inter-day $(n=6)$} \\
\hline & $\begin{array}{c}\text { Observed } \\
\text { con. }(\mu \mathrm{g} / \mathrm{ml})\end{array}$ & $\begin{array}{c}\text { Accuracy } \\
\text { Bias (\%) }\end{array}$ & $\begin{array}{l}\text { Precision } \\
\text { RSD (\%) }\end{array}$ & $\begin{array}{c}\text { Observed } \\
\text { con. }(\mu \mathrm{g} / \mathrm{ml})\end{array}$ & $\begin{array}{c}\text { Accuracy } \\
\text { Bias (\%) }\end{array}$ & $\begin{array}{c}\text { Precision } \\
\text { RSD (\%) }\end{array}$ \\
\hline \multicolumn{7}{|l|}{ 5-FU } \\
\hline 0.1 & $0.100 \pm 0.01$ & -0.403 & 2.298 & $0.098 \pm 0.01$ & -2.166 & 6.898 \\
\hline 0.5 & $0.499 \pm 0.01$ & -0.262 & 2.300 & $0.513 \pm 0.03$ & 2.601 & 6.343 \\
\hline 1 & $1.014 \pm 0.02$ & 1.357 & 2.337 & $1.041 \pm 0.06$ & 4.055 & 6.081 \\
\hline 5 & $4.986 \pm 0.08$ & -0.272 & 1.578 & $4.866 \pm 0.22$ & -2.670 & 4.617 \\
\hline 10 & $10.02 \pm 0.07$ & 0.184 & 0.686 & $10.09 \pm 0.33$ & 0.903 & 3.236 \\
\hline 50 & $50.05 \pm 0.05$ & 0.100 & 0.091 & $50.01 \pm 0.06$ & 0.014 & 0.117 \\
\hline \multicolumn{7}{|l|}{ 5-FDHU } \\
\hline 0.1 & $0.098 \pm 0.01$ & -1.923 & 9.729 & $0.095 \pm 0.01$ & -4.625 & 8.980 \\
\hline 0.5 & $0.506 \pm 0.01$ & 1.225 & 2.305 & $0.513 \pm 0.02$ & 2.563 & 4.851 \\
\hline 1 & $0.994 \pm 0.03$ & -0.638 & 2.657 & $1.053 \pm 0.10$ & 5.305 & 9.268 \\
\hline 5 & $4.945 \pm 0.16$ & -1.092 & 3.264 & $4.958 \pm 0.44$ & -0.850 & 8.871 \\
\hline 10 & $10.10 \pm 0.21$ & 0.988 & 2.061 & $10.00 \pm 0.54$ & 0.021 & 5.413 \\
\hline 50 & $50.11 \pm 0.63$ & 0.225 & 0.126 & $50.09 \pm 0.13$ & 0.172 & 0.269 \\
\hline
\end{tabular}

Data are expressed as the means \pm S.D. $(n=6)$ Precision $(\% R S D)=S . D \cdot / C_{o b s}{ }^{*} 100$. Accuracy $(\%$ Bias $)=\left(C_{o b s}-C_{n o m}\right) / C_{n o m}{ }^{*} 100$.

\section{White Blood Cell, Hemoglobin, Platelet, Creatine, and Hepatic Function After RT 0.5 Gy or 2 Gy With 5-FU Treatment}

The serum concentrations of white blood cell $(\mathrm{K} / \mu \mathrm{l})$, hemoglobin $(\mathrm{g} / \mathrm{dL})$, platelet $(\mathrm{K} / \mu \mathrm{l})$, creatine $(\mathrm{mg} / \mathrm{dl})$ and alanine aminotransferase $(\mathrm{U} / \mathrm{L})$ levels between the 5 -FU-treated versus (vs.) 0.5 Gy followed by 5-FU-treated vs. 2 Gy followed by 5-FUtreated were $6.42 \pm 0.26$ vs. $6.28 \pm 0.15$ vs. $6.09 \pm 2.71,8.02 \pm 1.20$ vs. $8.80 \pm 1.56$ vs. $8.55 \pm 2.54,401.8 \pm 127.4$ vs. $427.8 \pm 110.9$ vs. $367.0 \pm 136.8,0.20 \pm 0.17$ vs. $0.55 \pm 0.26$ vs. $0.10 \pm 0$ and $64.4 \pm$ 22.9 vs. $75.0 \pm 32.1$ vs. $61.8 \pm 28.4$, respectively. There were no significant differences between the 5-FU-treated versus (vs.) 0.5 Gy followed by 5-FU-treated vs. 2 Gy followed by 5-FUtreated groups.

\section{DISCUSSION}

5-FU is commonly used to enhance RT effects (Wolmark et al., 2000; Bosset et al., 2006). The RT-PK phenomenon of 5-FU is a phenomenon in which systemic 5-FU could be modulated by local irradiation with a change in the AUC of 5-FU in plasma (Hsieh et al., 2011; Hsieh et al., 2015). However, whether the metabolism of 5-FU is modulated by RT is still unclear (Hsieh et al., 2015). Here, local pelvic irradiation reduced the $\mathrm{AUC}_{\text {plasma }}$ values of $5-\mathrm{FU}$ by $24 \%$ and $35 \%$ at $0.5 \mathrm{~Gy}$ and $2 \mathrm{~Gy}$, respectively. The $\mathrm{AUC}_{\text {plasma }}$ values of 5FDHU, the metabolite of 5-FU, also declined by $21 \%$ at $0.5 \mathrm{~Gy}$ and $52 \%$ at $2 \mathrm{~Gy}$. Additionally, the $\mathrm{AUC}_{\text {bile }}$ values of $5-\mathrm{FU}$ increased by $37 \%$ and $69 \%$ at 0.5 Gy and 2 Gy, respectively. Meanwhile, the $\mathrm{AUC}_{\text {bile }}$ values of 5-FDHU increased by $40 \%$ at $0.5 \mathrm{~Gy}$ and $248 \%$ at 2 


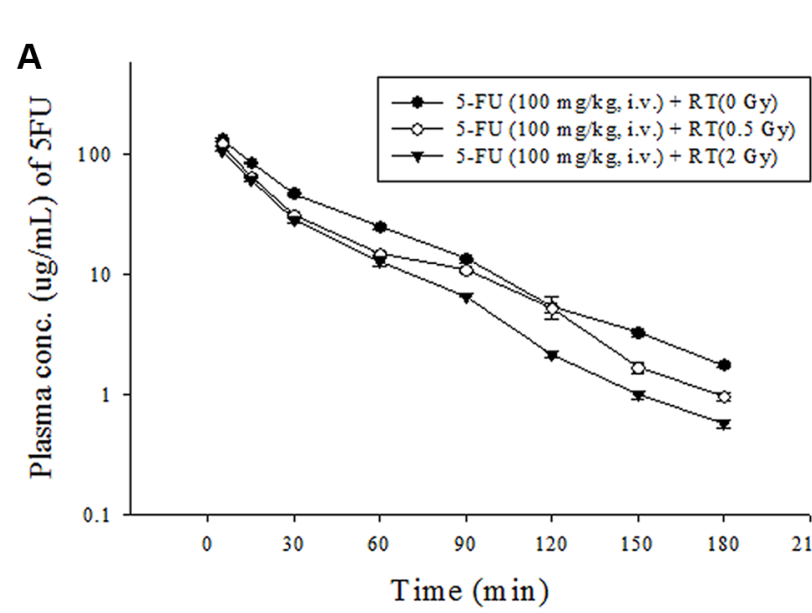

B

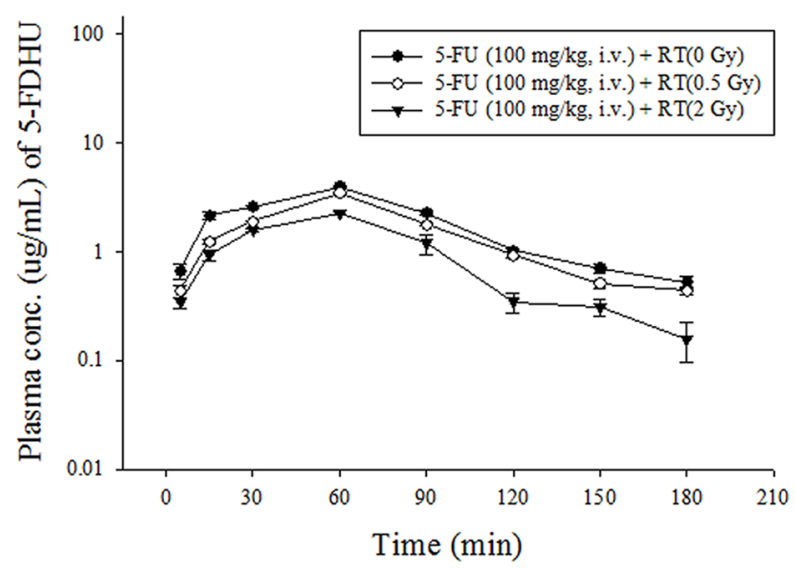

FIGURE 3 | (A) Mean plasma concentration-time curve of 5-FU $(\bullet)$ in rat blood after 5-FU administration (100 mg/kg, iv) alone, 5-FU (100 mg/kg, i.v.) + RT (0.5 Gy) (O) and 5-FU (100 mg/kg, i.v.) + RT (2 Gy) (V). (B) Mean plasma concentration-time curve of 5 -FDHU $(\bullet)$ in rat blood after 5 -FU administration (100 mg/kg, iv) alone, 5-FU (100 mg/kg, i.v.) + RT (0.5 Gy) (O) and $5-F U(100 \mathrm{mg} / \mathrm{kg}$, i.v. $)+\mathrm{RT}(2 \mathrm{~Gy})(\boldsymbol{\nabla}) .(\mathrm{n}=6)$.
Gy. The current study reconfirmed the RT-PK phenomenon of $5-\mathrm{FU}$ and suggested that the metabolite of 5-FU, 5FDHU, can be modulated by RT, with similar trends in the two compounds.

There are correlations between plasma levels of 5-FU and treatment outcomes (Milano et al., 1994; Gamelin et al., 1998). Higher AUC values of 5-FU are associated with impressive survival and response rates (Milano et al., 1994; Gamelin et al., 1998). However, $31 \%$ to $34 \%$ of treated patients have doselimiting toxicities (Meta-Analysis Group In et al., 1998). Concomitant administration of 5-FU and RT increases the rate of observed grade 3 or higher acute mucositis (Strigari et al., 2016). Bazan et al. (2013) reported that acute hematologic toxicity in patients treated with pelvic RT concomitant with 5FU was $8 \%$ higher than in those undergoing RT alone. Prolonged tumor retention of 5-FU and the enhanced cytotoxicity followed by RT was reported by Blackstock et al. (1996).

Actually, as the ratio of AUC of 5-FU/5-FDHU increased, the risk of adverse events in cancer patients also increased (Di Paolo et al., 2001). The current study showed that the 5-FU/5-FDHU AUC ratios in the sham, 0.5 Gy and 2 Gy group were 13, 13 and 18, respectively. Additionally, pelvic irradiation significantly increased the respective Vss of 5-FU by $16.7 \%$ at $0.5 \mathrm{~Gy}$ and $17.7 \%$ at 2 Gy. According to the above data (Blackstock et al., 1996; Di Paolo et al., 2001), the current RT-PK phenomenon supported that RT plus 5-FU could cause more adverse events than 5-FU alone by increasing the ratio of AUC of 5-FU/5-FDHU and the Vss of 5-FU. Additionally, the off-target dose also modulates the PK of 5-FU and contributes to the toxicity during CCRT.

Bocci et al. (2006) noted that there are significant correlations between the AUCs of 5-FU and 5-FDHU. Additionally, 5-FDHU plasma levels may correlate with DPD activity weakly but significantly (Bocci et al., 2006). Meanwhile, DPD activity is determined by the CL of 5-FU in plasma, and high-5-FU CL predicts lower toxicity and poor outcome for colorectal cancer patients (Gusella et al., 2009). The current study showed that pelvic irradiation, whether $0.5 \mathrm{~Gy}$ or $2 \mathrm{~Gy}$, increased the CL of 5FU. Meanwhile, the AUC $\mathrm{Alasma}_{\text {of }}$-FDHU declined by both irradiation doses. Additionally, the CL of 5-FDHU also increased

TABLE 5 | Pharmacokinetic parameters of 5-FU (100 mg/kg, i.v.) and 5-FDHU from rat plasma.

\begin{tabular}{|c|c|c|c|c|c|c|c|}
\hline \multirow[t]{2}{*}{ Parameter } & \multirow[t]{2}{*}{ Unit } & \multicolumn{2}{|c|}{ Control } & \multicolumn{2}{|c|}{$\begin{array}{c}\text { Whole pelvic RT } \\
0.5 \text { Gy }\end{array}$} & \multicolumn{2}{|c|}{$\begin{array}{c}\text { Whole pelvic RT } \\
2 \text { Gy }\end{array}$} \\
\hline & & 5-FU & 5-FDHU & 5-FU & 5-FDHU & 5-FU & 5-FDHU \\
\hline AUC & $\min \mu \mathrm{g} / \mathrm{ml}$ & $5114 \pm 109$ & $372.7 \pm 8.43$ & $3904 \pm 84.8^{\star \star}$ & $292.6 \pm 3^{\star \star}$ & $3307 \pm 68.5^{\star \star}$ & $181.4 \pm 10^{\star \star}$ \\
\hline $\mathrm{C}_{0}$ & & $169.3 \pm 8.52$ & - & $168.3 \pm 11.6$ & - & $142.1 \pm 3,1^{\star \star}$ & - \\
\hline $\mathrm{C}_{\max }$ & $\mu \mathrm{g} / \mathrm{ml}$ & - & $3.94 \pm 0.02$ & - & $3.45 \pm 0.1^{* *}$ & - & $2.27 \pm 0.1^{\star *}$ \\
\hline$T_{\max }$ & $\min$ & - & 60 & - & 60 & - & 60 \\
\hline Vss & $\mathrm{ml} / \mathrm{kg}$ & $742.3 \pm 26.1$ & - & $866.1 \pm 37^{\star \star}$ & - & $873.3 \pm 19^{\star \star}$ & - \\
\hline MRT & $\min$ & $38 \pm 1$ & $88 \pm 5$ & $34 \pm 1$ & $86 \pm 1$ & $29 \pm 0.45^{\star \star}$ & $72 \pm 3^{\star *}$ \\
\hline
\end{tabular}

$A U C$, area under the plasma concentration vs. time curve; $t 1 / 2$, terminal elimination phase half-life; Cmax, maximum observed plasma concentration; MRT, mean residence time; $C L$, total plasma clearance; Vss, volume of distribution at steady state. *significantly different from the without $R T$ group at $p<0.05$; * ${ }^{*}$ significantly different from without $R T$ group at $p<0.01$. 

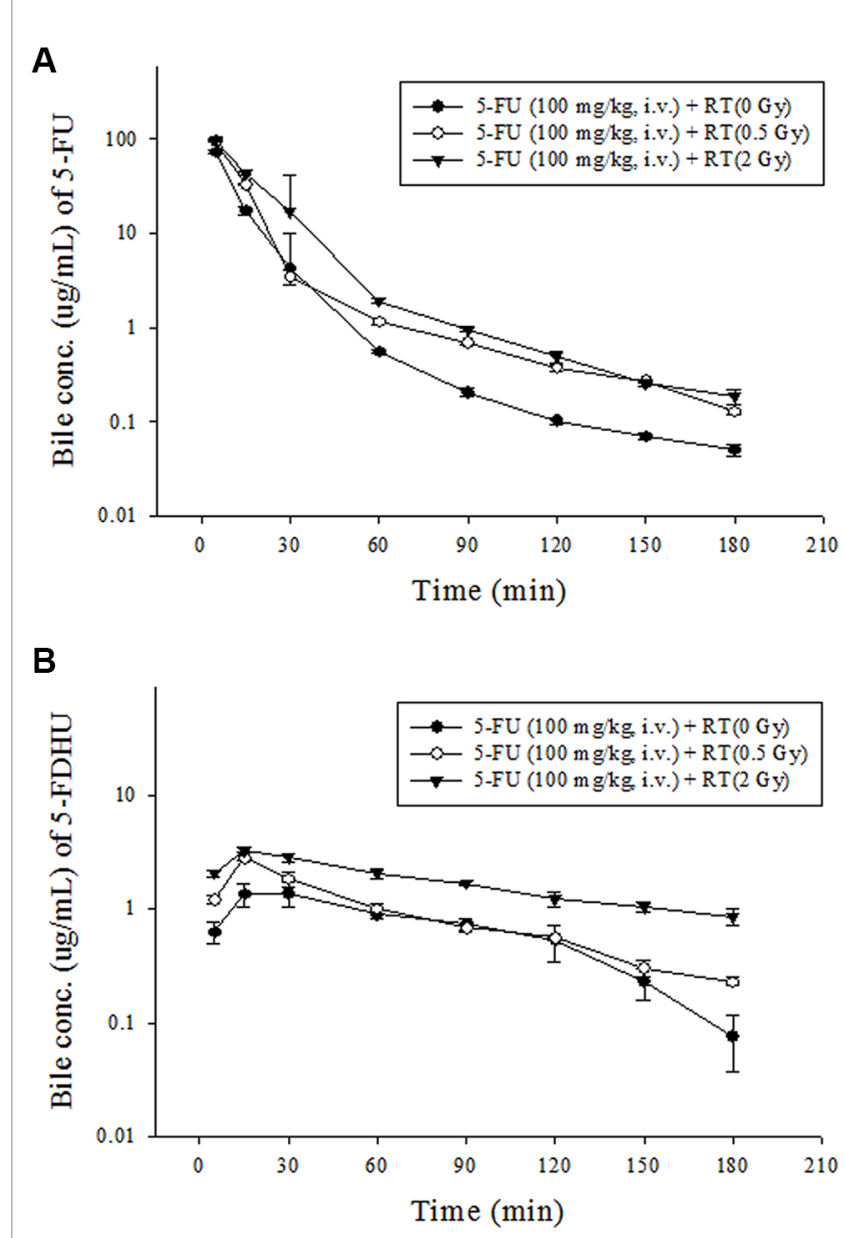

FIGURE 4 | (A) Mean bile concentration-time curves of 5-FDHU (•) in rat bile after 5-FU administration (100 mg/kg, iv) alone, 5-FU (100 mg/kg, i.v.) + RT (0.5 Gy) (O) and 5-FU (100 mg/kg, i.v.) + RT(2 Gy) ( $)$. (B) Mean bile concentration-time curves of 5-FDHU $(\bullet)$ in rat bile after 5 -FU administration (100 mg/kg, iv) alone, 5-FU (100 mg/kg, i.v.) + RT (0.5 Gy) (O) and 5-FU (100 $m g / k g$, i.v. $)+R T(2$ Gy) $(\boldsymbol{\nabla}) .(n=6)$. by irradiation. In contrast to the values in the plasma, the AUCs of 5-FU and 5-FDHU in the bile were increased by irradiation. This suggests that the activity of DPD may be decreased by irradiation and may be dose-dependent. Irradiation may reduce the toxicity of 5 -FU by decreasing the $\mathrm{AUC}_{\text {plasma }}$ of $5-\mathrm{FU}$ and increasing the bile excretion of 5-FU. However, the decreased AUC of 5-FU may cause poor clinical outcomes (Milano et al., 1994; Gamelin et al., 1998; Gusella et al., 2009), suggesting that RT followed by $5-\mathrm{FU}$ is not an ideal model in clinical practice.

There were no differences in the levels of TGF- $\beta 1$ and TNF- $\alpha$ between the RT and sham groups. However, the expression of MMP-8 increased by $100 \%$ at 2 Gy when compared with the sham group. Irradiation causes bystander signaling or abscopal effects through interleukins, cytokines, reactive oxygen species, TGF- $\beta 1$ and TNF- $\alpha$ (Chen et al., 2017). MMPs degrade extracellular matrix proteins. MMP activity can be upregulated by nitric oxide (NO)-mediated S-nitrosylation (Gu et al., 2002). MMP- 8 is an proinflammatory mediator and mediates inflammatory processes (Lee et al., 2014). MMP-8 acts directly on the proinflammatory cytokine TNF- $\alpha$, leading to cytokine production and inflammatory responses (Sriram and O'callaghan, 2007; Bahia and Silakari, 2010); MMP-8 is upregulated during hepatic ischemia and reperfusion injury (Cursio et al., 2002). A previous report suggested that MMP-8 may play a role in the RT-PK phenomenon (Hsieh et al., 2011). Interestingly, the current study confirmed the upregulated expression of MMP-8 in the plasma after local irradiation. However, there is very little known about the specific functions of MMP-8 in the RT-PK phenomenon.

Low-dose RT in clinical practice has become more popular with advanced radiotherapy techniques. However, off-target RT may produce unexpected or unwanted biological effects (Shueng et al., 2009; Darby et al., 2013). For example, the increased scattering of low-dose irradiation by esophageal stent during treatment increases the risk of aortic pseudoaneurysm formation and the risk of perforating the esophagus (Hou et al., 2015; Lu et al., 2018). An additional 1 Gy of radiation increases the incidence of major coronary events by $7.4 \%$ in breast cancer patients receiving RT

TABLE 6 | Pharmacokinetic parameters of 5-FU (100 mg/kg, i.v.) and 5-FDHU from rat bile.

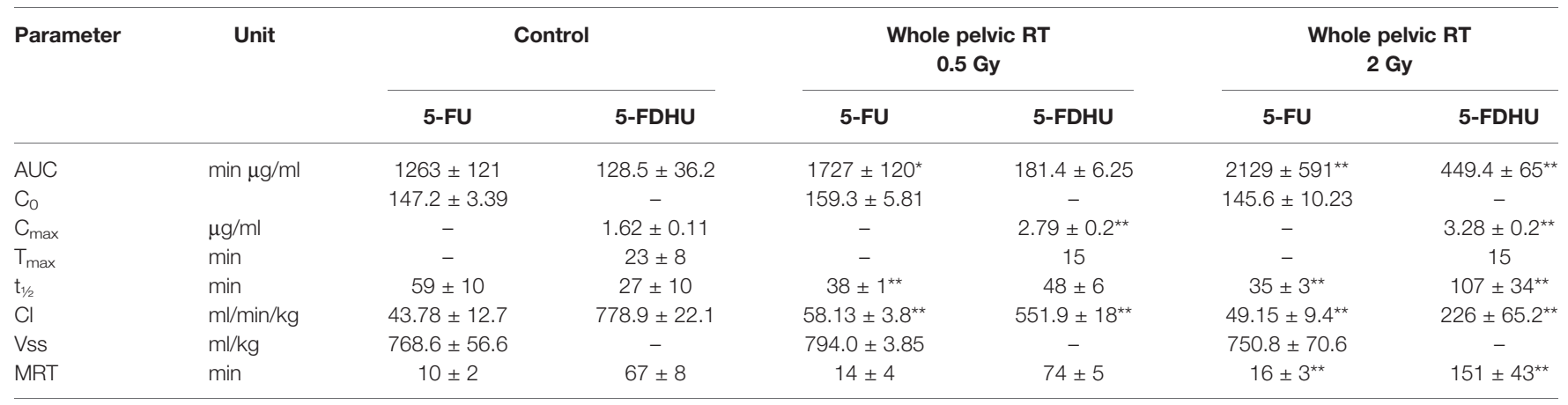

AUC, area under the plasma concentration vs. time curve; $11 / 2$, terminal elimination phase half-life; Cmax, maximum observed plasma concentration; MRT, mean residence time; $C L$, total plasma clearance; Vss, volume of distribution at steady state. *significantly different from the without $R T$ group at $p<0.05$; ** significantly different from the without $R T$ group at $p<0.01$. 
(Darby et al., 2013). However, the biological effects of low-dose RT are still unclear. Here, the current study confirmed that even lowdose irradiation can modulate the PK of anticancer drugs and their metabolites and can facilitate the excretion of drugs to the bile.

There were some limitations to this study. First, the current study was designed to examine the interaction between RT and PK of 5-FU and 5-FDHU but did not include the pharmacodynamics of 5-FU and 5-FDHU during RT. The current study confirmed there were no significant differences of toxicity effects between 5-FU-treated and RT plus 5-FUtreated groups. The current data was compatible with the previous report (Hsieh et al., 2011). These data also provided clues about systemic toxicology during the RT-PK phenomenon. Second, the delivery of RT in the current study was a single fraction. Further study to mimic clinical practice by using continued RT delivery to optimize the timing, duration, and dosing of 5-FU and 5-FDHU in the RT-PK phenomenon is warranted. Third, the possible mechanism was not included in the current study, although the current study noted that MMP-8 expression in the plasma was upregulated in the 5-FU and 5FDHU following RT group. However, we confirmed that the systemic PK of 5-FU and 5-FDHU could be modulated by RT with sequential administration. Finally, the decreased AUC of 5FU may cause poor clinical outcomes; nevertheless, it is not supported by the current experimental evidence. The current results just confirm that irradiation could modulate the pharmacokinetics of 5-FU and 5-FDHU. Further studies for detecting the optimal strategies, such as metronomic (Bocci and Kerbel, 2016), concurrent or sequential regimens for RT and 5FU, are clearly still required in the future.

The current results show that both conventional and lowdose irradiation can modulate the pharmacokinetics of 5-FU and 5-FDHU. Additionally, RT plus 5-FU could cause more adverse events than 5-FU alone by increasing the AUC ratio of 5-FU/5FDHU and the Vss of 5-FU. Irradiation may reduce the toxicity of 5 -FU by decreasing the AUC of 5-FU in the plasma and increasing the bile excretion of 5-FU. However, the decreased AUC of 5-FU may cause poor clinical outcomes, suggesting that a sequential regimen of RT and 5-FU is not an ideal model in

\section{REFERENCES}

(1991). Is there a need for more precise definitions of bioavailability? Conclusions of a consensus workshop, Munich, September 9, 1989; under the patronage of the F.I.P. Eur J Clin Pharmacol. 40, 123-126.

Bahia, M. S., and Silakari, O. (2010). Tumor necrosis factor alpha converting enzyme: an encouraging target for various inflammatory disorders. Chem. Biol. Drug Des. 75, 415-443. doi: 10.1111/j.1747-0285.2010.00950.x

Bazan, J. G., Luxton, G., Kozak, M. M., Anderson, E. M., Hancock, S. L., Kapp, D. S., et al. (2013). Impact of chemotherapy on normal tissue complication probability models of acute hematologic toxicity in patients receiving pelvic intensity modulated radiation therapy. Int. J. Radiat. Oncol. Biol. Phys. 87, 983-991. doi: 10.1016/j.ijrobp.2013.09.017

Blackstock, A. W., Kwock, L., Branch, C., Zeman, E. M., and Tepper, J. E. (1996). Tumor retention of 5-fluorouracil following irradiation observed using $19 \mathrm{~F}$ nuclear magnetic resonance spectroscopy. Int. J. Radiat. Oncol. Biol. Phys. 36, 641-648. doi: 10.1016/S0360-3016(96)00356-2 clinical practice. Hopefully, the current study sheds new light on these effects and increases our understanding of the effects of low dosage in the era of highly advanced RT.

\section{DATA AVAILABILITY STATEMENT}

All datasets generated for this study are included in the article.

\section{ETHICS STATEMENT}

The animal study was reviewed and approved by The Institutional Animal Experimentation Committee of National Yang-Ming University, Taipei, Taiwan, and by the Institutional Animal Care and Use Committee (IACUC, approval number 106DN22).

\section{AUTHOR CONTRIBUTIONS}

All of the authors have read and approved the final manuscript. Study design and data interpretation: J-HL, T-HT, and Y-JC. Data collection: J-HL. Data analysis: J-HL. Manuscript writing: J$\mathrm{HL}$ and C-HH. Manuscript revision: L-YW and H-YL. Acquisition of funding: T-HT, Y-JC, L-YW, and C-HH.

\section{ACKNOWLEDGMENTS}

This work was supported by grants from Far Eastern Memorial Hospital (FEMH 101-2314-B-418-010-MY3; FEMH 104-2314B-418-009-MY2; FEMH-2018-C-010; FEMH 107-2314-B-418007; FEMH 108-2314-B-418 -003 -MY2), the Ministry of Science and Technology, Taiwan (MOST 101-2314-B-418-010-MY3; MOST 104-2314-B-418-009-MY2; MOST106-2113-M-010-002; MOST 107-2314-B-418-007; MOST 108-2314-B-418 -003 -MY2), and the NYMU-FEMH Joint Research Program (106DN22, 107DN20, 108DN31).

Bocci, G., and Kerbel, R. S. (2016). Pharmacokinetics of metronomic chemotherapy: a neglected but crucial aspect. Nat. Rev. Clin. Oncol. 13, 659673. doi: $10.1038 /$ nrclinonc. 2016.64

Bocci, G., Danesi, R., Di Paolo, A. D., Innocenti, F., Allegrini, G., Falcone, A., et al. (2000). Comparative pharmacokinetic analysis of 5-fluorouracil and its major metabolite 5-fluoro-5,6-dihydrouracil after conventional and reduced test dose in cancer patients. Clin. Cancer Res. 6, 3032-3037.

Bocci, G., Barbara, C., Vannozzi, F., Di Paolo, A., Melosi, A., Barsanti, G., et al. (2006). A pharmacokinetic-based test to prevent severe 5-fluorouracil toxicity. Clin. Pharmacol. Ther. 80, 384-395. doi: 10.1016/j.clpt.2006.06.007

Bosset, J. F., Collette, L., Calais, G., Mineur, L., Maingon, P., Radosevic-Jelic, L., et al. (2006). Chemotherapy with preoperative radiotherapy in rectal cancer. $N$ Engl. J. Med. 355, 1114-1123. doi: 10.1056/NEJMoa060829

Chen, Y. J., Tsai, T. H., Wang, L. Y., and Hsieh, C. H. (2017). Local radiotherapy affects drug pharmacokinetics-exploration of a neglected but significant uncertainty of cancer therapy. Technol. Cancer Res. Treat 16, 705-716. doi: $10.1177 / 1533034617737011$ 
Cursio, R., Mari, B., Louis, K., Rostagno, P., Saint-Paul, M. C., Giudicelli, J., et al. (2002). Rat liver injury after normothermic ischemia is prevented by a phosphinic matrix metalloproteinase inhibitor. FASEB J. 16, 93-95. doi: 10.1096/fj.01-0279fje

Darby, S. C., Ewertz, M., Mcgale, P., Bennet, A. M., Blom-Goldman, U., Bronnum, D., et al. (2013). Risk of ischemic heart disease in women after radiotherapy for breast cancer. N Engl. J. Med. 368, 987-998. doi: 10.1056/NEJMoa1209825

Di Paolo, A., Danesi, R., Falcone, A., Cionini, L., Vannozzi, F., Masi, G., et al. (2001). Relationship between 5-fluorouracil disposition, toxicity and dihydropyrimidine dehydrogenase activity in cancer patients. Ann. Oncol. 12, 1301-1306. doi: 10.1023/A:1012294617392

Elsasser, T., and Scholz, M. (2007). Cluster effects within the local effect model. Radiat. Res. 167, 319-329. doi: 10.1667/RR0467.1

Ezzeldin, H., and Diasio, R. (2004). Dihydropyrimidine dehydrogenase deficiency, a pharmacogenetic syndrome associated with potentially life-threatening toxicity following 5-fluorouracil administration. Clin. Colorectal Cancer 4, 181-189. doi: 10.3816/CCC.2004.n.018

Fisher, B., Wolmark, N., Rockette, H., Redmond, C., Deutsch, M., Wickerham, D. L., et al. (1988). Postoperative adjuvant chemotherapy or radiation therapy for rectal cancer: results from NSABP protocol R-01. J. Natl. Cancer Inst. 80, 2129. doi: 10.1093/jnci/80.1.21

Gamelin, E., Boisdron-Celle, M., Delva, R., Regimbeau, C., Cailleux, P. E., Alleaume, C., et al. (1998). Long-term weekly treatment of colorectal metastatic cancer with fluorouracil and leucovorin: results of a multicentric prospective trial of fluorouracil dosage optimization by pharmacokinetic monitoring in 152 patients. J. Clin. Oncol. 16, 1470-1478. doi: 10.1200/JCO.1998.16.4.1470

Gu, Z., Kaul, M., Yan, B., Kridel, S. J., Cui, J., Strongin, A., et al. (2002). Snitrosylation of matrix metalloproteinases: signaling pathway to neuronal cell death. Science 297, 1186-1190. doi: 10.1126/science.1073634

Gusella, M., Frigo, A. C., Bolzonella, C., Marinelli, R., Barile, C., Bononi, A., et al. (2009). Predictors of survival and toxicity in patients on adjuvant therapy with 5-fluorouracil for colorectal cancer. Br. J. Cancer 100, 1549-1557. doi: 10.1038/ sj.bjc. 6605052

Heggie, G. D., Sommadossi, J. P., Cross, D. S., Huster, W. J., and Diasio, R. B. (1987). Clinical pharmacokinetics of 5-fluorouracil and its metabolites in plasma, urine, and bile. Cancer Res. 47, 2203-2206.

Hou, P. Y., Teng, C. J., Chung, C. S., Liu, C. Y., Huang, C. C., Chang, M. H., et al. (2015). Aortic pseudoaneurysm formation following concurrent chemoradiotherapy and metallic stent insertion in a patient with esophageal cancer. Med. (Baltimore) 94, e862. doi: 10.1097/MD.0000000000000862

Hsieh, C. H., Hsieh, Y. J., Liu, C. Y., Tai, H. C., Huang, Y. C., Shueng, P. W., et al. (2010). Abdominal irradiation modulates 5-Fluorouracil pharmacokinetics. J. Transl. Med. 8, 29. doi: 10.1186/1479-5876-8-29

Hsieh, C. H., Liu, C. Y., Hsieh, Y. J., Tai, H. C., Wang, L. Y., Tsai, T. H., et al. (2011). Matrix metalloproteinase- 8 mediates the unfavorable systemic impact of local irradiation on pharmacokinetics of anti-cancer drug 5-Fluorouracil. PloS One 6, e21000. doi: 10.1371/journal.pone.0021000

Hsieh, C. H., Hou, M. L., Chiang, M. H., Tai, H. C., Tien, H. J., Wang, L. Y., et al. (2013). Head and neck irradiation modulates pharmacokinetics of 5fluorouracil and cisplatin. J. Transl. Med. 11, 231. doi: 10.1186/1479-587611-231

Hsieh, C. H., Hou, M. L., Wang, L. Y., Tai, H. C., Tsai, T. H., and Chen, Y. J. (2015). Local pelvic irradiation modulates Pharmacokinetics of 5-Fluorouracil in the plasma but not in the Lymphatic System. BMC Cancer 15, 316. doi: 10.1186/s12885-015-1344-4

Lee, G., and Goosens, K. A. (2015). Sampling blood from the lateral tail vein of the rat. J. Vis. Exp., 18 (99), e52766. doi: 10.3791/52766
Lee, E. J., Han, J. E., Woo, M. S., Shin, J. A., Park, E. M., Kang, J. L., et al. (2014). Matrix metalloproteinase- 8 plays a pivotal role in neuroinflammation by modulating TNF-alpha activation. J. Immunol. 193, 2384-2393. doi: 10.4049/ jimmunol.1303240

Lu, Z., Zhang, R., and Diasio, R. B. (1993). Dihydropyrimidine dehydrogenase activity in human peripheral blood mononuclear cells and liver: population characteristics, newly identified deficient patients, and clinical implication in 5fluorouracil chemotherapy. Cancer Res. 53, 5433-5438.

Lu, Y. F., Chung, C. S., Liu, C. Y., Shueng, P. W., Wu, L. J., Hsu, C. X., et al. (2018). Esophageal metal stents with concurrent chemoradiation therapy for locally advanced esophageal cancer: safe or not? Oncologist 23, 1426-1435. doi: 10.1634/theoncologist.2017-0646

Mcleod, H. L., Sludden, J., Murray, G. I., Keenan, R. A., Davidson, A. I., Park, K., et al. (1998). Characterization of dihydropyrimidine dehydrogenase in human colorectal tumours. Br. J. Cancer 77, 461-465. doi: 10.1038/bjc.1998.73

Meta-Analysis Group In, C., Levy, E., Piedbois, P., Buyse, M., Pignon, J. P., Rougier, P., et al. (1998). Toxicity of fluorouracil in patients with advanced colorectal cancer: effect of administration schedule and prognostic factors. $J$. Clin. Oncol. 16, 3537-3541. doi: 10.1200/JCO.1998.16.11.3537

Milano, G., Etienne, M. C., Renee, N., Thyss, A., Schneider, M., Ramaioli, A., et al. (1994). Relationship between fluorouracil systemic exposure and tumor response and patient survival. J. Clin. Oncol. 12, 1291-1295. doi: 10.1200/ JCO.1994.12.6.1291

Shueng, P. W., Lin, S. C., Chang, H. T., Chong, N. S., Chen, Y. J., Wang, L. Y., et al. (2009). Toxicity risk of non-target organs at risk receiving low-dose radiation: case report. Radiat. Oncol. 4, 71. doi: 10.1186/1748-717X-4-71

Sriram, K., and O'callaghan, J. P. (2007). Divergent roles for tumor necrosis factoralpha in the brain. J. Neuroimmune Pharmacol. 2, 140-153. doi: 10.1007/ s11481-007-9070-6

Strigari, L., Pinnaro, P., Carlini, P., Torino, F., Strolin, S., Minosse, S., et al. (2016). Efficacy and mucosal toxicity of concomitant chemo-radiotherapy in patients with locally-advanced squamous cell carcinoma of the head-and-neck in the light of a novel mathematical model. Crit. Rev. Oncol. Hematol. 102, 101-110. doi: 10.1016/j.critrevonc.2016.04.004

Van Kuilenburg, A. B., Van Lenthe, H., Wanders, R. J., and Van Gennip, A. H. (1997). Subcellular localization of dihydropyrimidine dehydrogenase. Biol. Chem. 378, 1047-1053.

Wasternack, C. (1980). Degradation of pyrimidines and pyrimidine analogspathways and mutual influences. Pharmacol. Ther. 8, 629-651. doi: 10.1016/ 0163-7258(80)90079-0

Wolmark, N., Wieand, H. S., Hyams, D. M., Colangelo, L., Dimitrov, N. V., Romond, E. H., et al. (2000). Randomized trial of postoperative adjuvant chemotherapy with or without radiotherapy for carcinoma of the rectum: National Surgical Adjuvant Breast and Bowel Project Protocol R-02. J. Natl. Cancer Inst. 92, 388-396. doi: 10.1093/jnci/92.5.388

Conflict of Interest: The authors declare that the research was conducted in the absence of any commercial or financial relationships that could be construed as a potential conflict of interest.

Copyright (C) 2020 Liu, Tsai, Chen, Wang, Liu and Hsieh. This is an open-access article distributed under the terms of the Creative Commons Attribution License (CC BY). The use, distribution or reproduction in other forums is permitted, provided the original author(s) and the copyright owner(s) are credited and that the original publication in this journal is cited, in accordance with accepted academic practice. No use, distribution or reproduction is permitted which does not comply with these terms. 